\title{
Personal Rapid Transit Applications at Airports
}

\author{
Peter J. Muller ${ }^{1}$ \\ ${ }^{1}$ Member, ASCE, P.E., M.S., Olsson Associates, 143 Union Boulevard, Suite 700, \\ Lakewood, CO 80228; PH (720) 962-6072; FAX (720) 962-6195; email: \\ pmuller@oaconsulting.com
}

\section{Abstract}

Airports appear to be ideal candidates for personal rapid transit (PRT) implementation. Questions relating to PRT's cost and capacity are addressed by comparing PRT to traditional systems such as automated people movers (APM), moving sidewalks and electric carts. In most cases (all when the cost of time is included) PRT handles the required capacity at less cost. It also offers numerous other benefits that might make it the system of choice even with higher costs.

PRT may allow airports to completely reinvent themselves. In addition to improving security, this could potentially allow in-transit airline transactions and change the focus of airport terminals from ticketing and check-in to waiting and concessions. If extended to connect the airport to downtown, PRT could also potentially improve the transit service in the neighborhoods it passes through.

\section{Introduction}

Personal rapid transit (PRT) is defined as follows (Advanced Rapid Transit Association, 2003):

- Direct origin-to-destination service with no need to transfer or stop at intermediate stations.

- Small vehicles (called transportation pods or T-Pods in this paper) available for the exclusive use of an individual or small group traveling together by choice.

- Service available on demand by the user rather than on fixed schedules.

- Fully automated vehicles (no human drivers) which can be available for use 24 hours a day, 7 days a week.

- Vehicles captive to a guideway that is reserved for their exclusive use. 
- Small (narrow and light) guideways are usually elevated but also can be at or near ground level or underground.

- Vehicles able to use all guideways and stations on a fully connected PRT network.

PRT-like systems have been operating at Morgantown, West Virginia in a college environment for some thirty years. PRT and PRT-like systems have been operating in Holland for years including one at Schipol Airport since 1997. BAA plans to have a PRT system operational at London Heathrow Airport in 2006. Airports appear to be ideal candidates for PRT because they already use automated transit to move large numbers of people, they do not have cross-jurisdictional issues and do not suffer from the "not in my back yard" (NIMBY) syndrome.

Before airports embrace PRT three basic questions must be answered:

1. Is PRT robust (can it provide reliable service)?

2. What does PRT cost?

3. What is the capacity of PRT?

Morgantown and Schipol already supply some of the answers to the first question. Initial verification of PRT operational reliability, construction and operating costs in a high capacity application (11,000 passengers per day (Lowson, 2005)) should be available from Heathrow by the end of 2007. The major difference between PRT and APM systems is the size and number of the vehicles and the increased complexity of the vehicle movement (T-Pods bypass non-destination stations). The increased complexity of vehicle movement is accommodated by control software running on today's more powerful computers. This software has been in development, simulated and operational testing for many years and is not expected to present operational problems. PRT systems can thus reasonably be expected to provide reliable service matching that of APM systems.

This paper focuses on the second two questions and compares the answers with the cost and capacity of other airport surface transportation systems. While it appears that PRT should cost (capital, operating and maintenance) substantially less than APM systems for the same capacity, PRT systems have numerous additional benefits over APM potentially making PRT the system of choice even if its costs were higher. These advantages are anticipated to include:

- Reduced trip times (walking + waiting + travel)

- Reduced space requirements and construction time (smaller infrastructure)

- Increased redundancy (more numerous guideways and stations) 
- More flexible guideways (small radii)

- Seated travel

- Increased security (no crowded stations or vehicles)

- Potential to conduct airline and/or security transactions while traveling

- $\quad$ Reduced way finding (T-Pod takes travelers to their destination)

The PRT costs used in this study are an average of costs quoted by three different PRT vendors (2getthere, SkyWeb Express and ULTra - see Figure 1). It must be noted that there was variation in the prices quoted and that not all the systems are suited or adaptable to all of the scenarios described. In addition these vendors have limited or no public domain system installation and operational experience.

APM costs (which varied greatly) have been obtained from various sources including previous airport studies as well as APM vendors. The Denver International Airport (DIA) APM costs were the actual costs incurred in 1994 factored to 2004 costs.

\section{Hypothetical Large Volume Comparison}

In order to highlight the differences between PRT and APM, a hypothetical situation has been analyzed. PRT and APM systems have been conceptually designed to serve an identical origin and destination two miles apart. The origin and destination are each

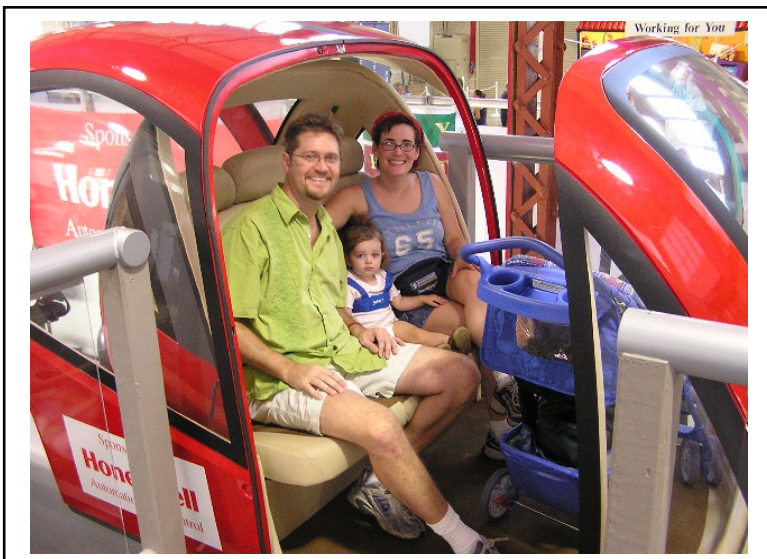

SkyWeb Express

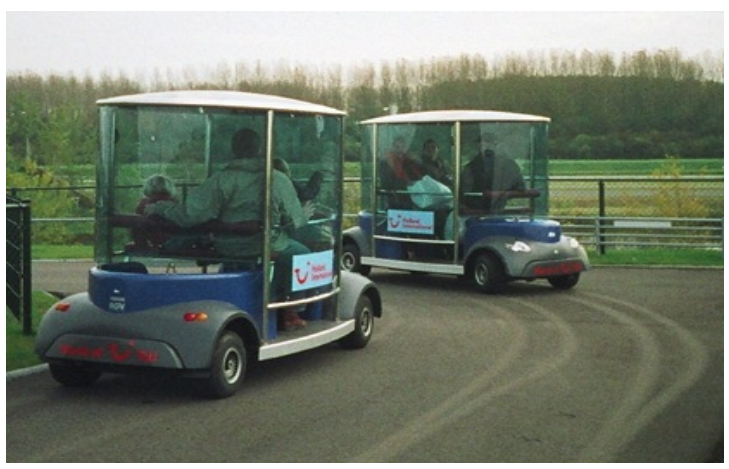

2getthere

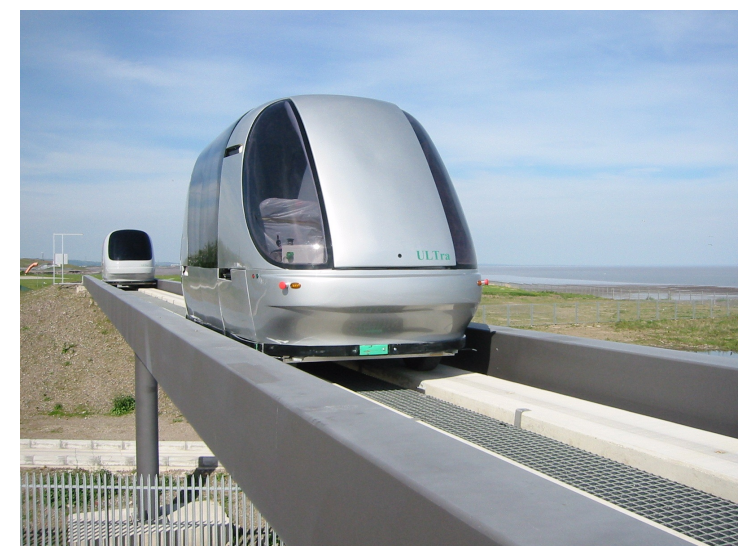

ULTra

Figure 1. PRT systems contributing to the average PRT costs used. 
comprised of a parking lot approximately 610m x 396m (2,000' x 1,300'). An intermediate stop is assumed to be required for the convenience of some passengers. The calculations are for peak flow in one direction only. This peak flow is assumed to be 5,000 passengers per hour per direction (pphpd). While the parking lot may in reality need to be a parking structure of similar area to generate such flows, no account is taken of travel times using elevators or stairs between floors.

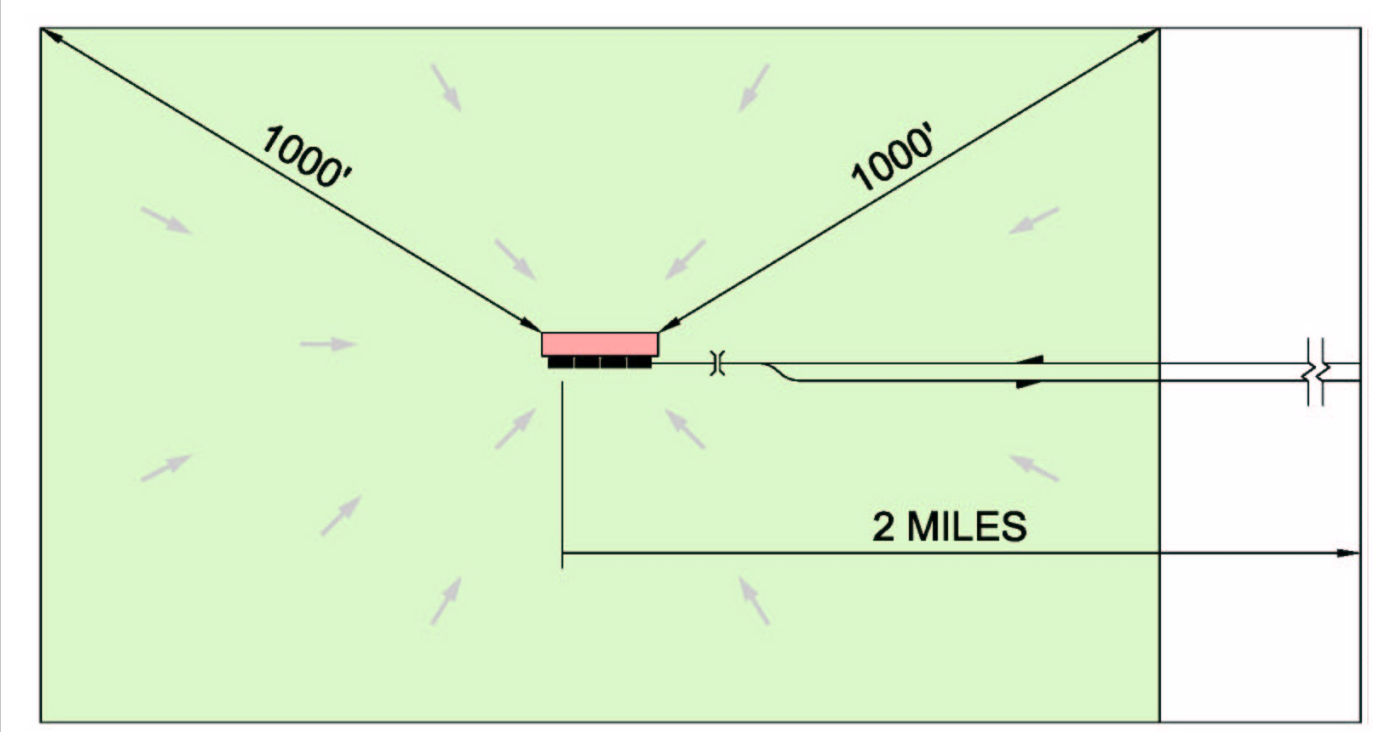

Figure 2. APM origin station

The APM solution comprises 4 trains each comprised of 4 cars. The car capacity is 50 passengers and the trains operate at a 120second headway (time between trains). The trains are assumed to operate at a maximum speed of $40 \mathrm{mph}$. Two guideways are needed (one in each direction). They are collocated to optimize station and guideway construction. Three stations are needed - one each at the origin and destination and one at the intermediate stop. Figure 2 shows the origin (or destination) layout.

The PRT solution requires 450 T-Pods operating at headways of two seconds and a speed of $40 \mathrm{~km} / \mathrm{h}(25 \mathrm{mph})$. One vendor has permission from the British Rail Authority to carry members of the public at speeds of $40 \mathrm{~km} / \mathrm{h}(25 \mathrm{mph})$ and 3 second headways. The reduction to two seconds while maintaining the top speed at $40 \mathrm{~km} / \mathrm{h}$ (25mph) is considered conservative since most PRT vendors anticipate higher speeds and headways as low or lower than one second. The PRT solution accommodates 28 stations - twelve each at the origin and destination and four at the intermediate stop. It requires four guideways, two of which have been collocated for simplicity (there is not much benefit to collocation). Figure 3 shows the origin (or destination) layout. 


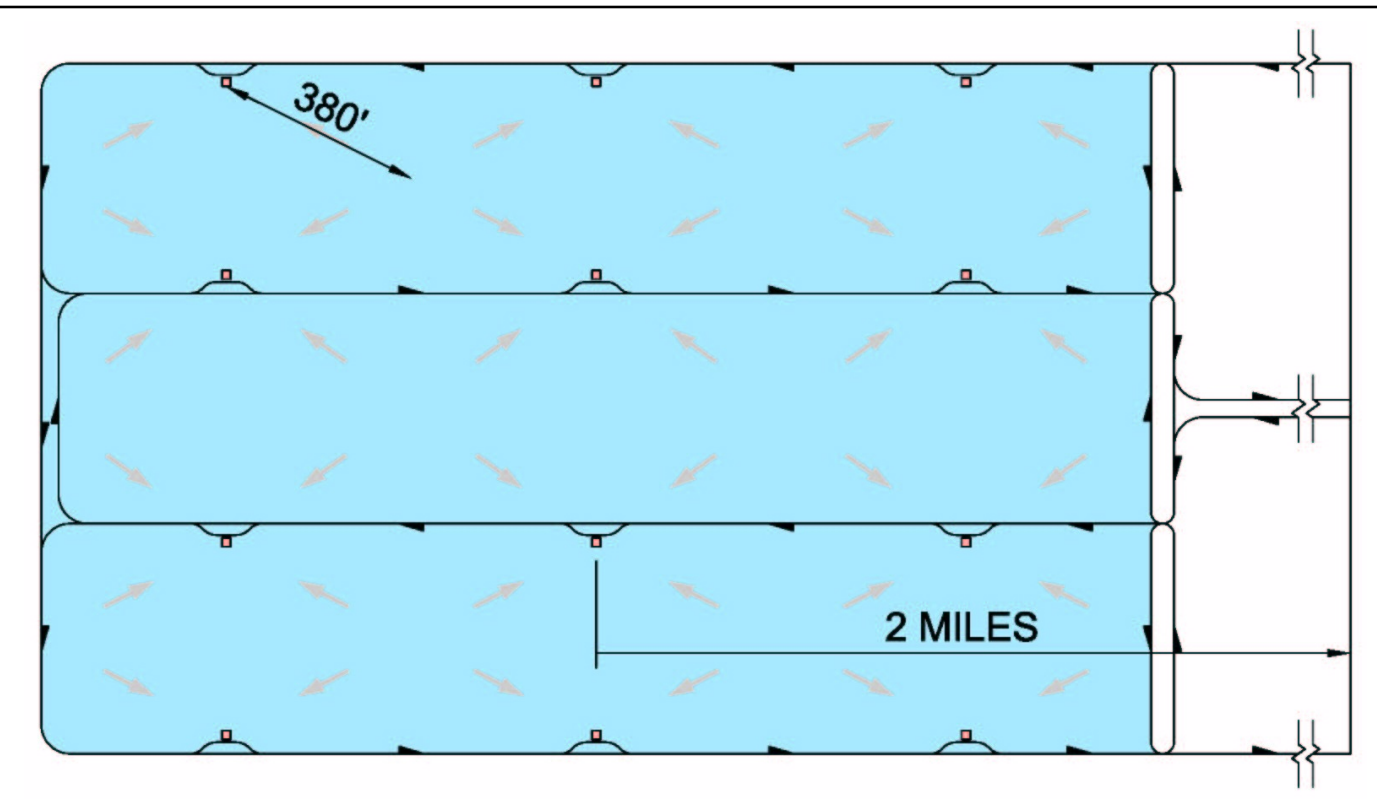

Figure 3. PRT origin stations.

Table 1 compares the two systems. The APM system operates full and has little spare capacity. The PRT system was designed to operate at a vehicle occupancy of 2.0 (50\% full). If the system was backed up, people would share rides, thus increasing occupancy and providing spare capacity.

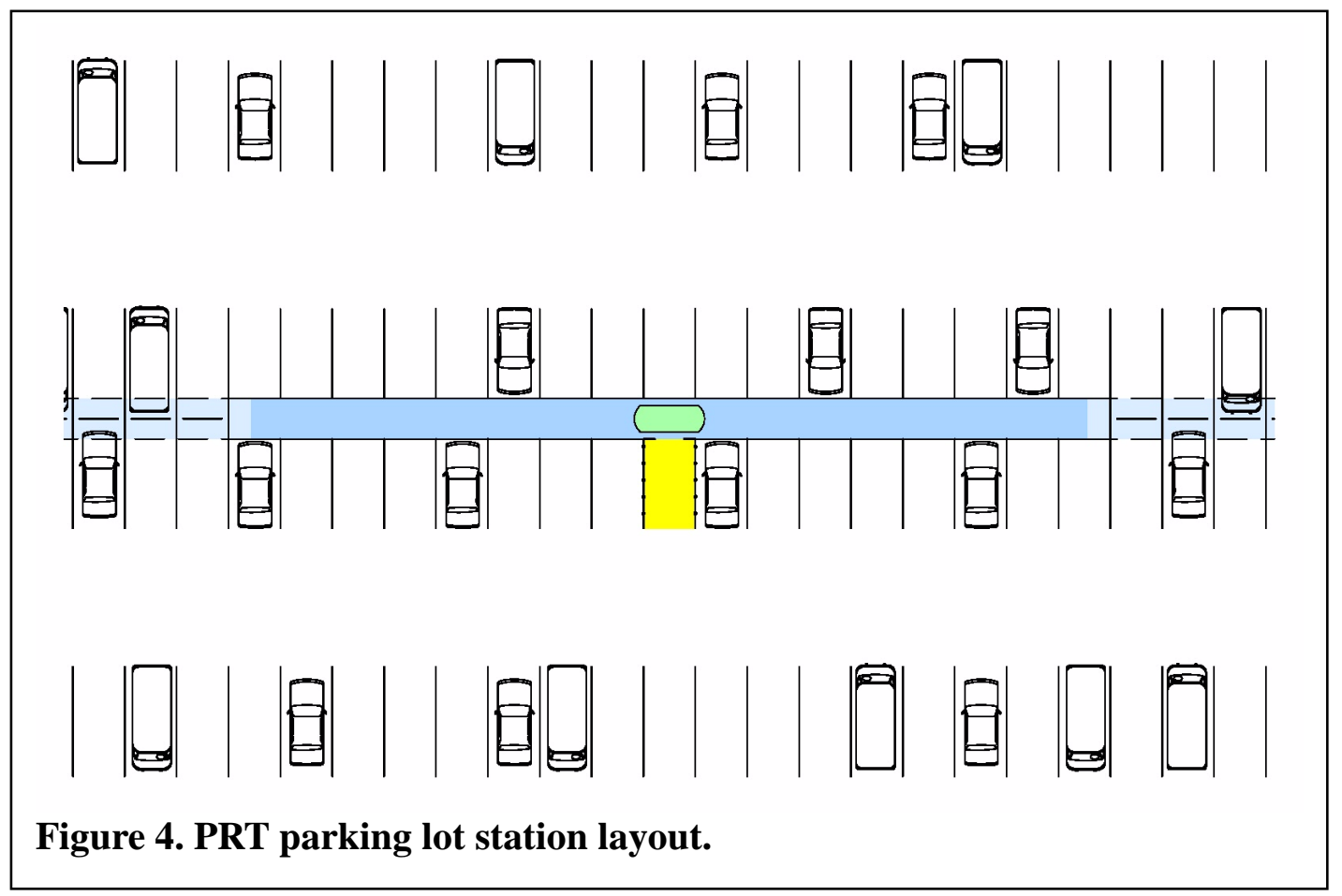


Table 1. APM/PRT Comparison for Hypothetical Origin and Destination

\begin{tabular}{|c|c|c|c|}
\hline Time (seconds) & APM & PRT & $\begin{array}{r}\text { PRT as \% } \\
\text { of APM } \\
\end{array}$ \\
\hline Walking & 114 & 45 & 39 \\
\hline Waiting & 60 & 10 & 17 \\
\hline Boarding & 30 & 10 & 33 \\
\hline Traveling & 260 & 300 & 115 \\
\hline Exiting & 30 & 10 & 33 \\
\hline Walking & $\underline{114}$ & $\underline{45}$ & $\underline{39}$ \\
\hline Total trip time & 608 & 420 & 69 \\
\hline \multicolumn{4}{|l|}{ Average Number of people } \\
\hline Walking & 400 & 153 & 38 \\
\hline Standing & 445 & 14 & 3 \\
\hline Sitting & $\underline{0}$ & $\underline{417}$ & $\underline{\infty}$ \\
\hline Total people in system & 845 & 584 & 69 \\
\hline Maximum crowd size & 200 & 10 & 5 \\
\hline Maximum walking distance & $305 \mathrm{~m}\left(1,000^{\prime}\right)$ & $115 \mathrm{~m}\left(380^{\prime}\right.$ & 38 \\
\hline Spare capacity (pphpd) & 775 & 5,000 & 645 \\
\hline Number of vehicles & 19 & 520 & 2740 \\
\hline Total vehicle weight & $332 \mathrm{~T}$ & $250 \mathrm{~T}$ & 75 \\
\hline Total guideway length & $6.4 \mathrm{~km}$ (4 miles) & $16 \mathrm{~km}$ (10 miles) & 250 \\
\hline Capital cost & $\$ 175 \mathrm{M}$ & $\$ 131 \mathrm{M}$ & 75 \\
\hline Annual operating cost & $\$ 22 \mathrm{M}$ & $\$ 14 \mathrm{M}$ & 64 \\
\hline
\end{tabular}

Figure 4 shows how a PRT station takes up minimal space in a parking lot. If the lot has $6 \mathrm{~m}(20$ ') long stalls, the $2.1 \mathrm{~m}$ (seven foot) wide guideway leaves room for $4.8 \mathrm{~m}$ (16') long compact vehicle stalls. Alternatively, if the full-size stalls are less than $6 \mathrm{~m}$ (20') long, the guideway can be offset to one side of the centerline between stalls and parallel parking can be provided adjacent to the at-grade portion of the guideway. Note that, once the guideway is more than about five feet above grade, nose-in parking can be permitted under the guideway with barrier curbs preventing drive through.

The PRT system requires numerous small vehicles. However, it is noteworthy that their total weight is less than the total weight of the few large APM vehicles. The difference in capital cost of the two systems is no doubt somewhat attributable to the economies of producing numerous small vehicles.

The PRT system has excellent redundancy in that a problem at any station or on any portion of guideway can only prevent access to 3 of the 27 stations and reduce capacity by a maximum of $50 \%$. A problem effecting the collocated guideways or any 
one of the APM stations on the other hand, has the capability to shut the entire system down.

PRT offers obvious security advantages by simply reducing the crowd size, which virtually eliminates the system from being a potential terrorist target. A PRT system would be ideal for transporting people through a security checkpoint since travelers could await their turn in seated comfort outside the security building (see Figure 7). This could eliminate the vulnerability posed by present check-in systems involving crowds of people with unscreened luggage.

\section{Comparison With Existing DIA APM System}

A conceptual design was undertaken for a PRT system that could have been constructed in place of the existing APM system at DIA had PRT been available at the time (Muller et al, 2005). The PRT system was constrained to the space occupied by the APM system - the four stations and the tunnels connecting them. While the PRT system requires four guideways to serve the same number of passengers served by the existing APM system, it was found that these guideways could be contained within the existing tunnels. In fact much less vertical clearance is required such that the PRT tunnel requirement is less than half the depth of the APM tunnels.

While the PRT guideway layout in each station is fairly complex (see Figure 5) to allow a T-Pod entering on any guideway to depart in either direction on any guideway, the PRT stations can be contained within the footprint of the existing stations.

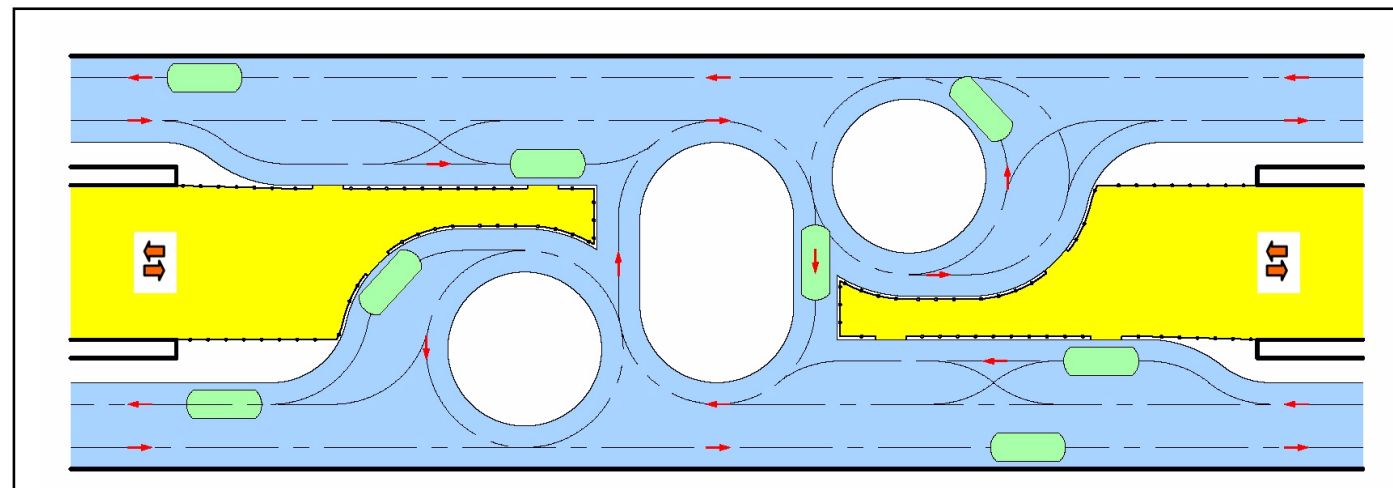

Figure 5. A PRT station replacing an APM station.

DIA provided the actual 1994 capital cost of the tunnels and the APM system. These were factored up to 2004 costs. DIA also provided the number of passengers currently carried and the current operating costs of the system.

Table 2 compares the two systems. Despite the slower maximum speed, the PRT travel time is less because it eliminates intermediate stops. Again PRT has more 
redundancy. A problem with one T-Pod or one guideway would reduce capacity by $33 \%$ as apposed to $50 \%$ or more with the APM system.

Table 2. APM/PRT Comparison at DIA

\begin{tabular}{|l|r|r|r|}
\hline & APM & PRT & $\begin{array}{r}\text { PRT as \% } \\
\text { of APM }\end{array}$ \\
\hline Passengers per year & $18,000,000$ & $18,000,000$ & 100 \\
\hline No. of vehicles & 27 & 124 & 459 \\
\hline No. of stations & 4 & 4 with 21 & 525 \\
& & bays & \\
\hline Guideway length & $3,690 \mathrm{~m}$ & $6,164 \mathrm{~m}$ & 194 \\
& $\left(12,100^{\prime}\right)$ & $\left(23,500{ }^{\prime}\right)$ & \\
\hline Ave. wait time (seconds) & 80 & 20 & 25 \\
\hline Ave. travel time (seconds) & 218 & 115 & 53 \\
\hline Tunnel cost & $\$ 75,305,000$ & $\$ 37,652,500$ & 50 \\
\hline System cost & $\$ 126,204,200$ & $\$ 32,616,500$ & 26 \\
\hline Annual operating \& Maintenance cost & $\$ 10,950,000$ & $\$ 4,200,000$ & 38 \\
\hline
\end{tabular}

\section{PRT Use In DIA Concourse B}

PRT infrastructure and T-Pod size is such that a system could easily be accommodated inside the existing Concourses at DIA. Conceptual design of a system serving the 1,000m (3,300') long Concourse B was undertaken (Muller et al, 2005). It was found that two elevated guideways could serve ground level PRT stations (see Figure 5) located entirely within the footprints of the present moving sidewalks (which would no longer be necessary). The PRT system was assumed to accommodate $75 \%$ of the people using the concourse, eliminate the need for electric carts and reduce wheelchair use by $80 \%$.

Moving sidewalk, wheelchair and electric cart costs were estimated based on data supplied by DIA and interviews with operators.

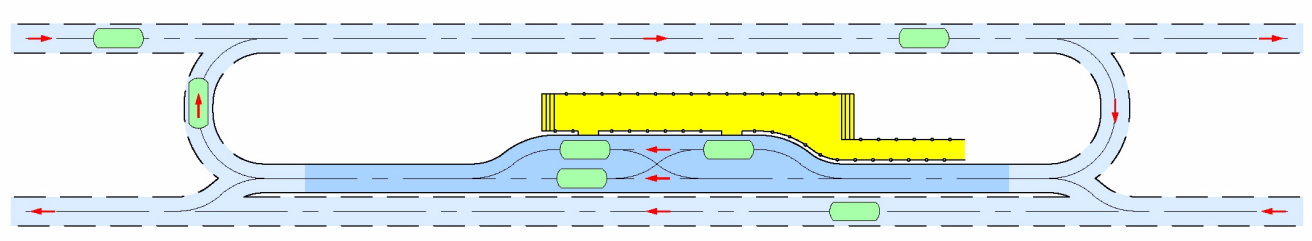

Figure 6. An in-concourse PRT station.

Table 3 compares the two systems. While the PRT capital costs are higher, the operating and maintenance costs are almost identical. Using the FAA's \$28.60/hour cost of time (FAA, 1998), the time savings easily compensate for the higher capital 
costs. Additional capital cost savings based on the fact that the PRT stations occupy less floor space than moving sidewalks have not been accounted for.

Table 3. Existing/PRT Comparison at DIA Concourse B

\begin{tabular}{|l|r|r|r|}
\hline & Existing Systems & PRT & $\begin{array}{r}\text { PRT as \% } \\
\text { of Existing }\end{array}$ \\
\hline No. of T-Pods & 0 & 20 & NA \\
\hline $\begin{array}{l}\text { No. of moving } \\
\text { sidewalks/stations }\end{array}$ & 4 sets of 4, 2 sets of 2 & 7,2 bay stations & NA \\
\hline No. of electric carts & 5 & 0 & 0 \\
\hline No. of wheelchairs & 35 & 7 & 20 \\
\hline Guideway length & 0 & $2,910 \mathrm{~m}\left(9,5500^{\prime}\right)$ & $\mathrm{NA}$ \\
\hline Average trip time (secs) & 200 & 114 & 57 \\
\hline Capital cost & $\$ 8,585,000$ & $\$ 16,082,000$ & 187 \\
\hline $\begin{array}{l}\text { Annual operating \& } \\
\text { maintenance cost }\end{array}$ & $\$ 2,510,136$ & $\$ 2,369,000$ & 94 \\
\hline
\end{tabular}

\section{Opportunities Offered by APM/PRT Systems}

PRT is such a unique form of transportation that there may be advantages to considering how it may allow airports to be designed differently from scratch. Instead of inserting PRT into the facilities and constraints imposed by other modes, it may be wise to rethink airports completely. This section is intended to promote thinking along those lines.

When APM systems were introduced to airports they allowed concourses to be separated from terminal buildings by aircraft parking aprons. APMs are ideally suited to transporting large groups of people from an origin to a destination along a corridor. The discussions above indicate that PRT is even more suited to that task. It accomplishes it in less time, for less cost while providing more comfort and security. However PRT is even better suited to transporting large numbers of people from numerous origins to numerous destinations along numerous routes.

One way in which PRT could provide enormous benefits to airports would be to combine the three systems described above. One PRT system linking numerous stations in remote parking lots to numerous stations in concourses would greatly facilitate airport surface transportation. However this would be like constraining all cars to operate on city streets and not allowing them the speed and convenience of freeways. Airports should use PRT as a tool to reinvent themselves.

If remote check-in kiosks were wirelessly incorporated into T-Pods, airline (and potentially some security) transactions could be undertaken in transit. If all security checking could be accomplished in dedicated screening facilities (see Figure 
7) between the remote parking lots and the airport buildings, the buildings would become much more secure (Muller, 2003). In addition, the need for a terminal building will have been mostly circumvented. However, this would result in most waiting being accomplished at the gate - probably not the best solution.

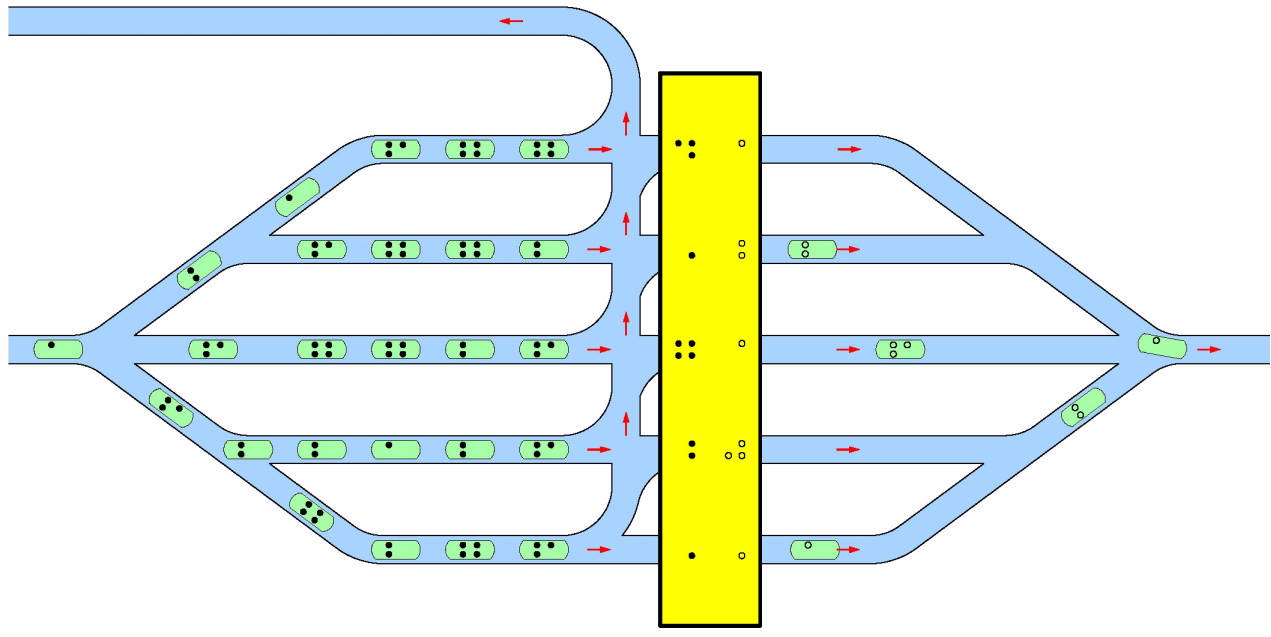

Figure 7. Dedicated security screening facility

A better solution may be to replace the terminal building with a centralized waiting facility incorporating expanded concessions. If the PRT system could communicate with passengers by cell phone or pager, it would be possible to coordinate just-in-time delivery of passengers to gates. This would almost eliminate waiting (and concessions) at the gate. Could it be that consolidating waiting and concessions in one place where public address systems are no longer needed would result in a better, more productive wait with more money being spent on improved concessions?

While it has been shown that PRT systems can be accommodated inside the long concourses found at today's large airports, there may be a better way. The reason the concourses are so long is that they need to connect to the centralized underground APM system. Small PRT tunnels containing one or two guideways could criss-cross an airport connecting numerous remote gates (see Figure 8 ) to the central concessions area and the remote parking lots. This could reduce aircraft taxi distances and the square footage of concourse needed.

Bags from arriving aircraft could be delivered directly from the aircraft to the concourse. To minimize crowding, passengers with checked bags could be asked to remain seated until notified that their bags have been offloaded. Notification could be accomplished by a system using on-board screens and tag scanning technology. Once all passengers with carry-ons only have deplaned, remaining passengers with checked 
luggage would be notified to deplane. In this way the aircraft will be unloaded in the same amount of time it presently takes.

Passengers with checked luggage will collect their luggage in the concourse and proceed directly to board a T-Pod. All passengers will be able to travel non-stop to the parking lot, rental car facility or other destination served by the PRT system.

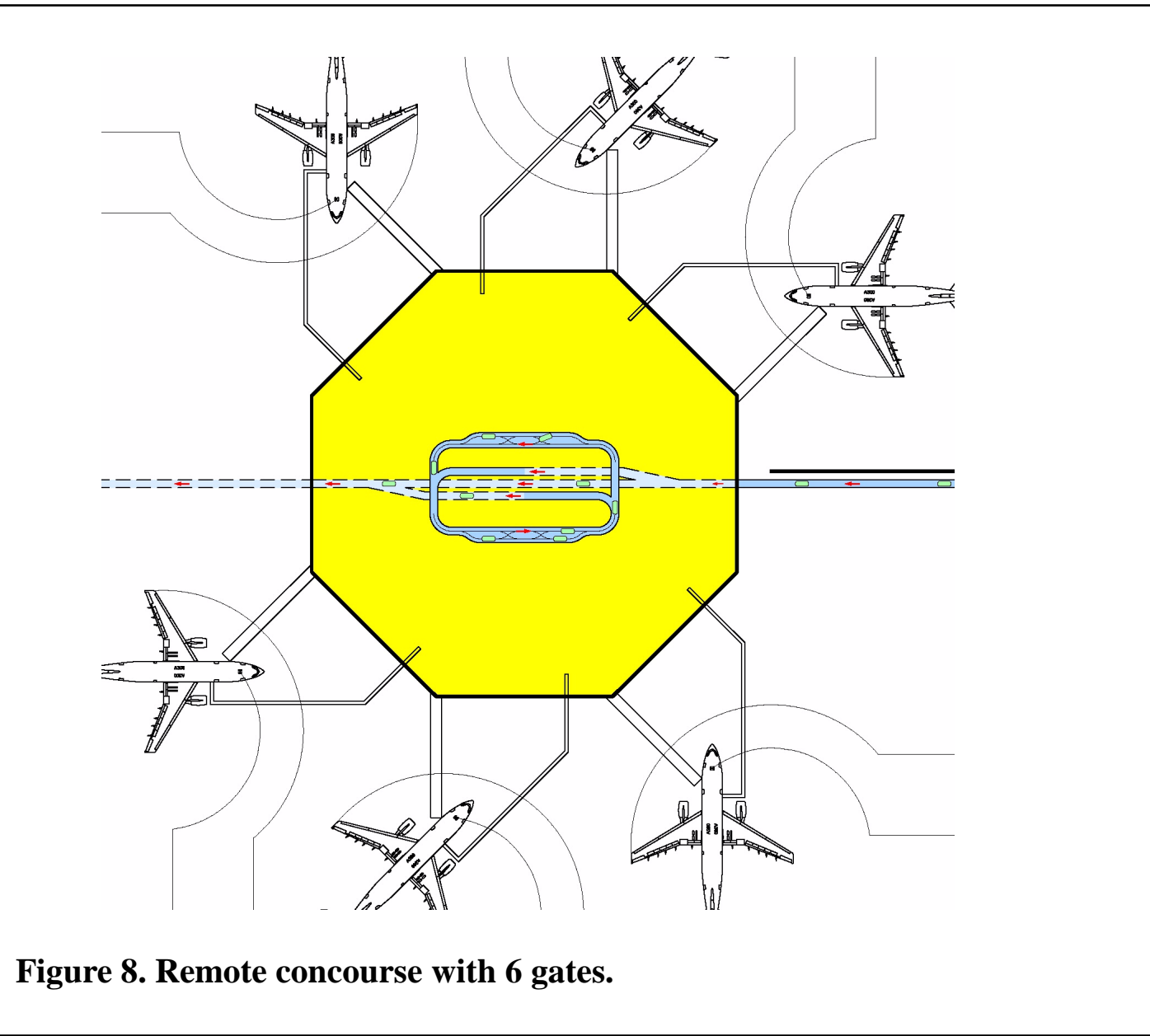

Connecting the airport to downtown is another PRT opportunity. Typically the rapid transit solution for this is light rail or commuter rail. In an effort to keep travel times low these systems usually have a small number of intermediate stations. They also usually operate in the same corridor in each direction. The net result is that these systems end up only providing good service for airport users and the community immediately adjacent to the stations.

On the other hand a PRT system would likely be comprised of four guideways connecting the airport to downtown. Each guideway could be located 450m (1,500') to $600 \mathrm{~m}(2,000$ ') apart and could include many stations. The system would thus provide excellent service to a swath approaching two miles wide between the airport 
and downtown. While trips to the airport would speed past intermediate stations, these stations would provide transit access with a walking distance typically less than $305 \mathrm{~m}(1,000$ ') and a wait time of a few seconds. The airport to downtown PRT system would truly enhance the transit access of those living between the airport and downtown unlike a conventional transit system, which would mostly just pass through the area.

\section{Conclusions}

Preliminary indications are that PRT will offer a very cost-effective and efficient alternative for airport surface transportation. While the costs, efficiencies and system reliability need to be proven in high-capacity applications, the PRT concept certainly offers interesting potential improvements to the way airports operate. PRT's flexibility (small infrastructure accommodating small radii) gives it the potential to be relatively easily retrofitted in existing facilities. At the same time, its personal service allows in-transit airline transactions which could allow airport terminals to refocus on concessions and waiting areas.

Using PRT to connect downtown to the airport or even the specific gate provides an opportunity for the local community to truly leverage the pass-through airport traffic. This in turn will possibly facilitate PRT gaining acceptance in the urban environment.

\section{References}

Advanced Transit Association (January 2003), "Personal Automated Transportation: Status and Potential of Personal Rapid Transit"

FAA APO Publication (1998 as updated on FAAAPO Website), "Economic Values for Evaluation of Federal Aviation Administration Investment and Regulatory Decisions."

Lowson, M.V. (2005), "Personal Rapid Transit for Airport Applications" Transportation Research Board Paper No. 05-0432.

Muller, P.J. (2003), "Reinventing Airports Using Personal Rapid Transit Pods (TPods)" International Air and Space Symposium and Exposition - The Next 100 Years. AIA Paper No. AIA-2003-2539.

Muller, P. J., Allee, W. (2005), "Personal Rapid Transit, an Airport Panacea?" Transportation Research Board Paper No. 05-0599. 